\title{
KNOWLEDGE MANAGEMENT SYSTEM MODEL PADA FORUM DISKUSI PETANI BUAH NAGA MENGGUNAKAN CMS phpBB
}

\author{
Anderias Eko Wijaya ${ }^{1}$ \\ ${ }^{1}$ STMIK Subang \\ Email: ${ }^{1}$ ekowjy09@yahoo.com
}

(Naskah masuk: 8 Juni 2016, diterima untuk diterbitkan: 23 Maret 2017)

\begin{abstract}
Abstrak
Buah naga adalah buah yang baru - baru ini dibudidayakan di Indonesia. Banyak yang gemar akan buah naga ini karena banyak sekali khasiatnya. Jenis buah naga juga bermacam - macam dan harga setiap jenis dan kualitasnya pun berbeda. Namun kualitas buah naga di Indonesia belum ada Standar Nasionalnya, untuk itu pendapat antar petani mengenai kualitas buah naga sangat bervariasi sehingga diperlukan adanya Knowledge Management System (KMS) dimana KMS merupakan sebuah System yang dibuat untuk mengelola pengetahuan. Dengan menggunakan Content Management System (CMS) php Buletin Board (phpBB) yang dasarnya adalah sebuah CMS yang mendukung untuk sebuah forum diskusi, maka diskusi antar petanipun dapat dilakukan dengan harapan para petani dapat saling bertukar pengetahuan - pengetahuan mereka mengenai kualitas buah naga. Dengan menggunakan proses dari model Knowledge Management yaitu SECI (Sosialization, Eksternalization, Combination, Internalization) maka hasil diskusi tersebut nantinya akan disimpulkan dan disimpan sebagai pengetahuan baru.
\end{abstract}

Kata kunci: buah naga, content management system, knowledge management system, PHP buletin board, SECI.

\section{Abstract}

Dragon fruit is a fruit that is new - this new cultivated in Indonesia. Many are fond of dragon fruit is because a lot of usefulness. Types of dragon fruit also wide - range and price of each type and quality vary. But the dragon fruit quality in Indonesia yet their National Standards, for that opinion among farmers about dragon fruit quality varies greatly so it is necessary to Knowledge Management System (KMS) where KMS is a system created to manage knowledge. By using Content Management System (CMS) PHP Bulletin Board (phpBB), which essentially is a CMS that supports a forum for discussion, the discussion among petanipun to do with the expectations of the farmers can exchange knowledge - knowledge about the quality dragon fruit. By using the process of Knowledge Management models are SECI (Sosialization, Eksternalization, Combination, Internalization) then the results of these discussions will be summarized and stored as a new knowledge.

Keywords: dragon fruit, content management system, knowledge management system, PHP buletin board, SECI.

\section{PENDAHULUAN}

Buah naga atau dragon fruit masuk atau mulai dikenal di Indonesia sekitar tahun 2000, dan bukan dari budidaya sendiri melainkan di impor dari Thailand. Buah naga sangat bermanfaat serta memiliki nilai gizi cukup tinggi. Buah naga mulai dikembangkan sekitar tahun 2001, dibeberapa daerah di Jawa Timur di antaranya Mojokerto, Pasuruan, Jember dan sekitarnya. Di Indonesia terdapat tiga jenis buah naga yaitu Hylocereus undatus (buah naga daging putih), Hylocereus polyrhizus (buah naga daging merah) dan Hylocereus costaricensis (buah naga daging sangat merah atau hitam) [1]. Buah naga atau dragon fruit mempunyai kandungan zat bioaktif yang bermanfaat bagi tubuh diantaranya antioksidan (dalam asam askorbat, betakaroten, dan anthosianin), serta mengandung serat pangan dalam bentuk pektin.
Selain itu, dalam buah naga terkandung beberapa mineral seperti kalsium, phosfor, besi, dan lain-lain. Vitamin yang terdapat di dalam buah naga antara lain vitamin B1, vitamin B2, vitamin B3, dan vitamin C [2].

Pada saat ini penentuan kualitas buah naga yang baik itu ditentukan oleh para petani sehingga masih sangat beragam kualitas yang baik itu seperti apa dengan berdasarkan pada versi masing-masing petani dan belum adanya System yang dapat menyimpan pengetahuan kualitas tersebut agar dimasa mendatang para generasi muda dapat mengetahui standar kualitas buah naga terbaik itu seperti apa. maka dari itu untuk memudahkan para petani dalam mengukur kualitas standar terbaik dan menyimpan pengetahuan tersebut untuk generasi selanjutnya.

Knowledge Management (KM) adalah suatu proses yang dapat membantu organisasi untuk 
mengidentifikasi, memilih, mengelola, menyebarkan dan mentransfer informasi dan keahlian penting yang merupakan bagian dari memori organiasi dan secara khusus menjadi bagian dari organisasi dalam cara yang tidak terstruktur [3].

phpBB merupakan sebuah aplikasi cms yang dapat digunakan untuk membuat sebuah forum. Dimana forum tersebut nantinya dapat digunakan untuk melakukan sebuah diskusi mengenai topik yang di angkat. Dalam penelitian ini penulis memanfaatkan phpBB sebagai sarana untuk mengimplementasikan knowledge management, dimana nantinya aplikasi phpBB akan digunakan untuk mencari pengetahuan baru berdasarkan konsep dan teori knowledge management.

\section{A. Identifikasi Masalah}

Berdasarkan penelitian awal yang dilakukan oleh penulis, ada beberapa masalah yang teridentifikasi. Masalah - masalah tersebut adalah sebagai berikut :

- Belum adanya SNI mengenai kualitas buah naga

- Penilaian kualitas buah naga masih berdasarkan penilaian petani buah naga, sehingga tidak ada keseragaman dalam penentuan kualitas BUAH NAGA

- Belum dimanfaatkannya teknologi dalam pengembangan budidaya buah naga.

- Tidak adanya forum untuk para petani untuk berdiskusi mengenai pengembangan budidaya buah naga.

B. Tujuan

Tujuan yang diperoleh dari aplikasi ini:

- Membuat Knowledge Management System untuk kualitas buah naga untuk menyeragamkan persepsi kualitas buah naga antar petani karena belum adanya standar nasional dan sebagai System yang akan menyimpan pengetahuan tersebut untuk generasi selanjutnya.

- Mengetahui kualitas buah naga berdasarkan komentar-komentar para petani buah naga.

C. Manfaat

Manfaat yang ingin dicapai dari pembuatan aplikasi ini:

- Sebagai alat bantu untuk menyimpan pengetahuan tentang kualitas buah naga

- Mendapatkan pengetahuan tentang kualitas buah naga

- Menyimpan pengetahuan tersebut untuk generasi selanjutnya.

D. Metodologi

Metodologi yang digunakan dalam penelitian ini adalah :

a. Studi Pustaka, Studi pustaka akan dilakukan pada seluruh proses pengerjaan yang terdiri dari studi pustaka tentang kualitas buah naga.

b. Analisis Masalah, Analisis terhadap kendala/ masalah yang sering terjadi pada kualitas buah naga, beserta teknik pemecahannya/ solusinya, yang nantinya akan diimplementasikan ke dalam perangkat lunak.

c. Analisis Perangkat Lunak, Kegiatan analisis perangkat lunak meliputi analisis spesifikasi perangkat lunak yang akan digunakan sebagai alat bantu penelitian.

d. Perancangan Perangkat Lunak, Perancangan perangkat lunak meliputi perancangan kelas dan perancangan antarmuka dari hasil analisis.

e. Implementasi Perangkat Lunak, Implementasi dari hasil analisis dan perancangan perangkat lunak.

f. Pengujian Perangkat Lunak, Pengujian terhadap perangkat lunak yang telah diimplementasikan.

\section{PUSTAKA}

\section{A. Definisi Knowledge}

Knowledge dalam hal ini tidak diterjemahkan, karena pengertian knowledge itu sendiri masih diperdebatkan. Knowledge bukan hanya pengetahuan. "Knowledge is neither data nor information, though it related to both, and the differences between these terms are often a matter of degree". [4].

B. Knowledge Management

Definisi Knowledge Management secara luas dalam arti mengelola pengetahuan sebagai “ ...management of organizational knowledge for creating business value and generating a competitive advantage." KM mengkomunikasikan dan menerapkan pengetahuan yang diperlukan dan berguna bagi pencapaian semua jenis tujuan bisnis [5]. Menurut Amrit Tiwana "Knowledge Management is the ability to create and retain greater value from core business competencies. " KM memberikan kemampuan untuk mencipta, menyelesaikan masalah bisnis partikular mencakup penciptaan dan penyebaran barang atau jasa inovatif, mengelola dan memperbaiki hubungan dengan para pelanggan, mitra dan pemasok; juga mengadministrasi serta meningkatkan praktek dan proses kerja. Maimunah berpandangan bahwa Knowledge Management merupakan aktivitas merencanakan, mengumpulkan dan mengorganisir, memimpin dan mengendalikan data dan informasi yang telah dimiliki oleh sebuah perusahaan yang kemudian digabungkan dengan berbagai pemikiran dan analisis dari berbagai macam sumber yang kompeten. Knowledge Management (KM) adalah suatu proses yang dapat membantu organisasi untuk mengidentifikasi, memilih, mengelola, menyebarkan dan mentransfer informasi dan keahlian penting yang merupakan bagian dari memori organiasi dan secara khusus menjadi bagian dari organisasi dalam cara yang tidak terstruktur

\section{Knowledge Management System (KMS)}


Knowledge Management System (KMS) merupakan System yang dibangun untuk mengelola manajemen pengetahuan (Knowledge Management) karena manajemen pengetahuan merupakan suatu hal yang sangat luas dan sangat kompleks.

KMS adalah System dari KM (Knowledge Management). Menurut KMS merupakan teknologi yang memungkinkan KM untuk berjalan dengan efektif dan efisien [6]. Definisi KMS yaitu sekelompok System informasi yang diaplikasikan untuk mengelola knowledge yang terdapat di dalam organisasi [7]. KMS merupakan System yang berbasiskan teknologi informasi yang dikembangkan untuk mendukung proses-proses inti dari KM yaitu, penciptaan knowledge (knowledge creation), penyimpanan knowledge (knowledge storage), pemindahan knowledge (knowledge transfer), dan pengaplikasian knowledge tersebut (knowledge application) dalam organisasi. Adanya penekanan terhadap tujuan utama dari KMS untuk meningkatkan keefektifan organisasional dengan adanya manajemen Systematis terhadap sebuah pengetahuan [8].

\section{SECI Model}

Nonaka dan Takeuchi, mengatakan bahwa "perusahaan yang sukses adalah yang konsisten menciptakan pengetahuan baru, membaginya keseluruh organisasi, dan semua orang tahu akan teknologi baru dan hasilnya"[9].

Ikujiro Nonaka dan Hirotaka Takeuchi pada tahun 1991 dan 1995, membedakan antara tacit knowledge dan explicit knowledge, dan membagi model konversi knowledge menjadi 4 cara sebagai berikut:

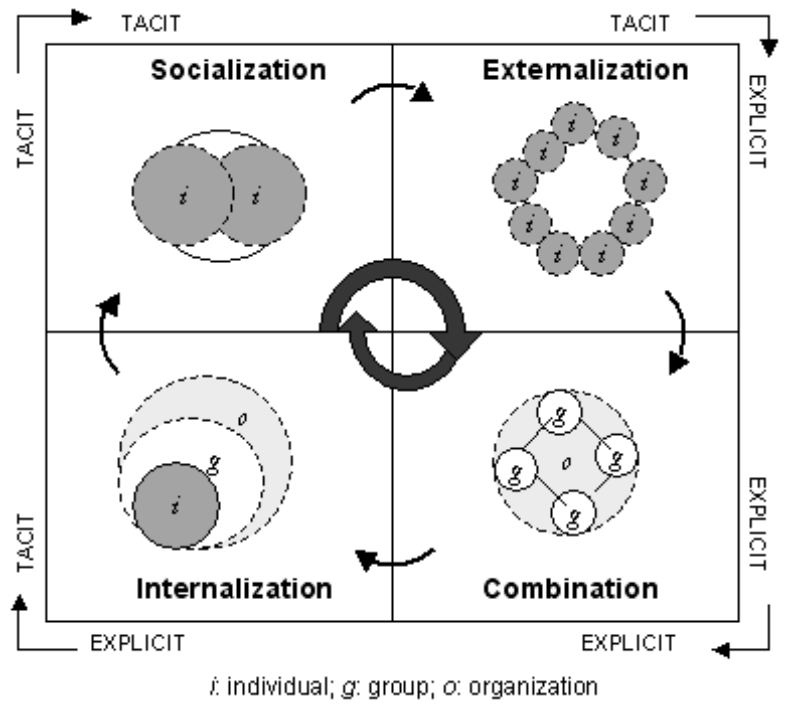

Gambar 1. SECI Model[9]

1) Tacit knowledge ke Tacit knowledge; disebut proses Socialization. Sosialisasi meliputi kegiatan berbagi tacit knowledge antar individu. Istilah sosialisasi digunakan karena tacit knowledge disebarkan melalui kegiatan bersama seperti tinggal bersama, meluangkan waktu bersama dan bukan melalui tulisan atau instuksi verbal.

2) Tacit knowledge ke Explicit knowledge; disebut proses Externalization. Eksternalisasi dipicu berturut - turut oleh rangkaian pemaknaan melalui dialog. Didalam dialog ini, penggunaan metafora digunakan sehingga memungkinkan anggota tim dapat mengartikulasikan perpektif dan tacit knowledge-nya yang sebelumnya sulit dikomunikasikan. Konsep - konsep yang diciptakan oleh tim dapat dikombinasikan dengan data yang ada serta pengetahuan dari luar untuk mencari spesifikasi yang lebih konkret dan dapat dibagi.

3) Explicit knowledge ke Explicit knowledge; disebut proses Combination. Dengan mengkombinasikan antar explicit knowledge yang dipunyai oleh individu lain dengan explicit knowledge yang dipunyai oleh diri sendiri.

4) Explicit knowledge ke Tacit knowledge; disebut proses Interlization. Individu harus mengidentifikasi pengetahuan yang relevan dengan kebutuhannya di dalam organizational knowledge tersebut. Dalam prakteknya, internalisasi dapat dilakukan dalam dua dimensi. Pertama, penerapan pengetahuan eksplisit dalam tindakan dan praktek langsung. Kedua, penguasaan pengetahuan eksplisit melalui simulasi, eksperimen, atau belajar sambil bekerja.

E. Knowledge Sharing

Knowledge Sharing dapat tumbuh dan berkembang apabila menemukan kondisi yang sesuai. Sedangkan kondisi tersebut ditentukan oleh 3 faktor kunci yaitu orang, organisasi dan tehnologi [10]. Sebab Knowledge Sharing dianggap sebagai hubungan atau interaksi sosial antar orang per-orang, sedangkan permasalahan organisasi memiliki dampak yang besar pada Berbagi Pengetahuan, dan tehnologi (informasi dan komunikasi) merupakan fasilitatornya [10].

Setelah pengetahuan telah dikumpulkan, lalu harus disimpan (stored) dan dibagikan (shared). Berbagi (sharing) pengetahuan melibatkan pemindahan pengetahuan dari satu (atau lebih) orang ke seseorang (atau lebih) lain. Berbagi pengetahuan sering kali menjadi perhatian utama dalam manajemen pengetahuan dan jarang dibicarakan dalam literatur. Tidak hanya sebagian besar organisasi mengabaikan pemikiran bahwa semua pengetahuan harus didokumentasikan, melainkan mereka juga harus siap untuk mengimplementasikan metode-metode yang berbeda untuk membagikan jenis-jenis pengetahuan yang berbeda.

Hal tersebut adalah perdebatan bahwa fokus dari Knowledge Management tidak hanya pada pendistribusian (distribution) tidak juga pada penyebaran (dissemination) pengetahuan, tetapi pada pembagiannya (share). Meskipun pengetahuan dapat di peroleh pada tahapan individu, agar dapat berguna harus dibagikan dalam suatu komunitas, yang 
seringkali digambarkan sebagai komunitas praktek. Contohnya, jika terdapat hanya satu orang yang mengetahui aturan dan prosedur organisasi, aturan dan prosedur seperti itu akan menjadi tidak berguna dan tak berarti. Disisi lain, aturan dan prosedur berasal dari komunitas dan ada dengan tepat untuk mengatur aktifitas kelompok. Berbagi pengetahuan (knowledge sharing) kemudian menjadi krusial ketika anggota baru datang dan yang lain keluar. Manajemen informasi tidak benar-benar memfokuskan pada pembagian informasi dan lebih diorientasikan kepada pengawasan, pemeliharaan, dan penyimpanan informasi. Seseorang juga dapat berpendapat bahwa kegunaan dan nilai dari informasi tidak bergantung sebanyak pada konsumsi dan pembagian kolektifnya: konsumsi dan penggunaan individunya dapat menjadi sangat efektif dari suatu sudut pandang organisasi. Sebenarnya, terlalu banyak pendistribusian informasi dapat mengarah pada kelebihan informasi yang dapat melumpuhkan tindakan. Berbagi pengetahuan dipahami, contohnya, oleh Bank Dunia sebagai kritikan untuk pembangunan ekonomi dan sebagai langkah penting berikutnya melampaui penyebaran informasi [11]. Pada akhirnya, siklus manajemen pengetahuan tidak lengkap juga tidak berhasil jika tidak ada usaha yang dibuat untuk memastikan penggunaan pengetahuan yang telah disimpan dan dibagikan. Di sisi lain, kesuksesan proyek Information Management dicapai ketika pemeliharaan dan pencarian informasi dijamin sementara kesuksesan program Knowledge Management pada akhirnya bergantung pada sharing (berbagi) pengetahuan [12].

F. Buah Naga

Buah naga (Hylocereus Undatus) adalah buah dari beberapa jenis kaktus dari marga Hylocereus dan Selenicereus. Buah ini berasal dari Meksiko, Amerika Tengah dan Amerika Selatan namun sekarang juga dibudidayakan di negara-negara Asia seperti Taiwan, Vietnam, Filipina, dan Malaysia. Buah tropis yang mempunyai banyak keunggulan di banding buah lainnya. Buah naga (dragon fruit) merupakan tanaman buah yang baru dibudidayakan di Indonesia mulai tahun 2000 dan banyak digemari oleh masyarakat karena memiliki khasiat dan manfaat serta nilai gizi cukup tinggi. Tanaman ini memiliki potensi yang baik dilihat dari permintaan yang terus meningkat diikuti teknik budidaya yang mudah dilakukan.

\section{G. Khasiat dan Kandungan Buah Naga}

Khasiat buah naga yang mengandung vit $\mathrm{C}$, beta karoten, kalsium dalam jumlah yang cukup banyak dan mengandung karbohidrat untuk menjaga dan menambah daya tahan tubuh agar tetap fit dan menjalani hari hari anda dengan lancar. Selain itu manfaat buah naga mempunyai serat yang sangat tinggi yang berguna untuk mengikat zat karsinogen penyebab terjadinya kanker dan melancarkan proses percernaan, zat-zat ini mentralkan racun dalam tubuh yang bisa berbahaya bagi tubuh bila terlalu banyak racun. Meningkatkan daya penglihatan dan mencegah hiprtensi.

\section{PEMBAHASAN}

\section{A. Knowledge Management Proceesses}

Proses indetifikasi kebutuhan knowledge yang ada pada petani buah naga. Selanjutnya proses penemuan (discovery) knowledge yang melibatkan para petani maupun pakar dengan cara mewawancarai mereka mengenai buah naga. Proses ini membicarakan ungkapan yang sering dikutip, "seandainya kita mengetahui apa yang kita tahu". Para petani diajak untuk mendiskusikan tentang apa yang mereka tahu.

Hasil atau penambahan (acquisition) knowledge ke para petani dari sumber eksternal. Penciptaan (creation) knowledge baru dapat dikerjakan dalam berbagai cara. Pertama, knowledge petani dapat digabungkan dengan knowledge petani lainnya untuk menciptakan knowledge yang baru. Dan yang kedua, informasi dapat dianalisis untuk menciptakan pengetahuan yang baru.

Knowledge yang terkumpul, harus disimpan (stored) dan didokumentasikan lalu dibagikan (shared). Berbagi (sharing) knowledge melibatkan pemindahan knowledge dari petani satu ke petani yang lainnya agar mereka bisa langsung menggunakan informasi yang di dapat.

Selanjutnya knowledge dapat digunakan disimpan kembali lalu dibagikan dan digunakan kembali, menjadi knowledge baru dan baru lagi.

\section{B. Analisa Kebutuhan Data}

Data masukan yang digunakan yaitu komentar yang diinputkan langsung oleh user pada forum diskusi yang telah dibuat dengan memberikan komentar terhadap topik yang sedang dibahas (kualitas buah naga) dan data disimpan dalam database.

Pendekatan SECI Model Dalam System ini penulis menggunakan SECI model yang dikemukakan oleh Ikujiro Nonaka dan Hirotaka Takeuchi pada tahun 1991 dan 1995 dimana ada 4 tahapan yang dilakukan yaitu:

1) Tahap pertama adalah proses socialization yaitu Tacit knowledge ke Tacit knowledge, pada tahap sosialisasi penulis melakukan tahap wawancara dengan para petani untuk mengumpulkan komentar - komentar tentang kualitas buah naga sehingga akan menghasilkan topik yang akan dibahas dalam forum diskusi.

2) Tahap kedua adalah proses eksternalisazion yaitu Tacit knowledge ke Explicit knowledge, pada tahap ini penulis akan mengangkat topik dalam forum diskusi dari hasil wawancara bersama para petani buah naga.

3) Tahap ketiga adalah Combination yaitu Explicit knowledge ke Explicit knowledge, setelah penulis mengangkat topik dari hasil wawancara maka pada tahap ini komentar - komentar yang 
diperoleh akan dimasukkan kedalam System dan disimpan dalam database.

4) Tahap keempat adalah Internalization yaitu Explicit knowledge ke Tacit knowledge, setelah komentar-komentar dimasukkan kedalam forum diskusi selanjutnya System akan menyatukan semua komentar - komentar tersebut dan menghasilkan ringkasan, dan ringkasan tersebut akan diterapkan oleh petani atau dijadikan bahan penelitian pakar. Selanjutnya didiskusikan lagi untuk memutuskan apakah akan menjadi pengetahuan baru atau masih perlu penyempurnaan lagi..

\section{Spesifikasi Pengguna}

System ini ditujukan untuk digunakan semua pihak khususnya petani buah naga yang ingin memberi kontribusi bisa berupa pertanyaan, pengalaman, permasalahan, teknik menanam, teknik memilih dan lain-lain yang akan didiskusikan di dalam forum diskusi. Sehingga hasil dari diskusi tersebut nantinya bisa bisa digunakan oleh petani sebagai pengetahuan baru.

\section{Arsitektur System}

System membutuhkan perangkat lunak lain sebagai penunjang agar system ini berjalan sesuai dengan fungsinya. Kebutuhan tesebut diantaranya:

a. Antar muka pemakai

Sebagai penunjang antarmuka pemakai dari perangkat lunak, diperlukan web browser, seperti: Internet Explorer, Mozilla Firefox dan sebagainya.

b. Antar muka komunikasi

Untuk komunkasi antara server dan client, maka diperlukan jaringan internet karena system yang dibangun berbasis web.

c. Aplikasi server

Dibutuhkan dua jenis server untuk memusatkan proses dari perangkat lunak, yaitu web server dan database server. Untuk web server-nya dapat menggunakan aplikasi Apache dan untuk database server-nya menggunakan MySQL. Aplikasi server ini akan mengatur request ke server dan juga respon terhadap dari server client. Analisa Fungsional System

Analisa yang akan diuraikan pada subbab ini terdiri dari beberapa tahapan antara lain adalah sebagai berikut:

\section{a. Context Diagram}

Context Diagram digunakan untuk menggambarkan proses kerja System secara umum. Context Diagram merupakan DFD (Data Flow Diagram) yang menggambarkan garis besar operasional System.

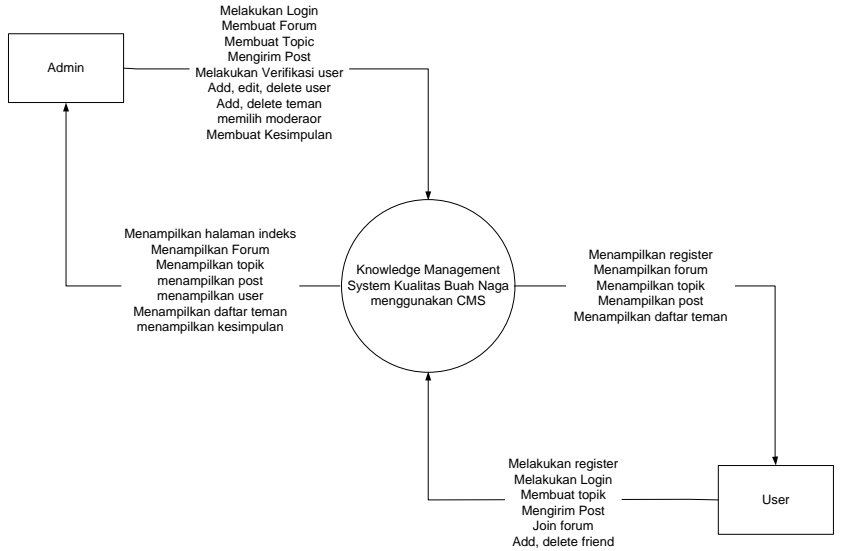

Gambar 4. Diagram Konteks

Tabel I.

Deskripsi Diagram Konteks

\begin{tabular}{|c|c|c|c|c|}
\hline No. & Entitas & Masukan & Keluaran & $\begin{array}{c}\text { Keteran } \\
\text { gan }\end{array}$ \\
\hline 1. & User & $\begin{array}{l}\text { Melakukan } \\
\text { daftar, } \\
\text { login, lalu } \\
\text { memberika } \\
\text { n komentar } \\
\text { mengenai } \\
\text { kualitas } \\
\text { buah naga } \\
\text { yang } \\
\text { diinputkan } \\
\text { langsung } \\
\text { oleh user } \\
\text { dalam } \\
\text { forum } \\
\text { diskusi dan } \\
\text { disimpan } \\
\text { di dalam } \\
\text { database. }\end{array}$ & $\begin{array}{l}\text { Ringkasan } \\
\text { dari } \\
\text { komentar } \\
- \\
\text { komentar } \\
\text { yang telah } \\
\text { diinputka } \\
\text { n }\end{array}$ & $\begin{array}{l}\text { user } \\
\text { adalah } \\
\text { orang } \\
\text { yang } \\
\text { melaku } \\
\text { kan } \\
\text { input } \\
\text { data } \\
\text { pada } \\
\text { System. }\end{array}$ \\
\hline 2. & Admin & $\begin{array}{l}\text { Mengamb } \\
\text { il } \\
\text { komentar } \\
- \\
\text { komentar } \\
\text { yang telah } \\
\text { diinputka } \\
\text { n untuk } \\
\text { dijadikan } \\
\text { pengetahu } \\
\text { an baru }\end{array}$ & $\begin{array}{l}\text { Pengetahua } \\
\mathrm{n} \text { baru dari } \\
\text { komentar } \\
\text { yang telah } \\
\text { diproses }\end{array}$ & $\begin{array}{l}\text { Admin } \\
\text { adalah } \\
\text { orang } \\
\text { yang } \\
\text { melaku } \\
\text { kan } \\
\text { pering } \\
\text { kasan } \\
\text { pada } \\
\text { System }\end{array}$ \\
\hline
\end{tabular}

b. Diagram Aliran Data (Data Flow Diagram)

Data Flow Diagram merupakan penjabaran dari Context Diagram secara lebih terperinci. Semua proses yang terjadi dapat dilihat pada gambar 5 . Analisa Data Flow Diagram sebagai berikut: 


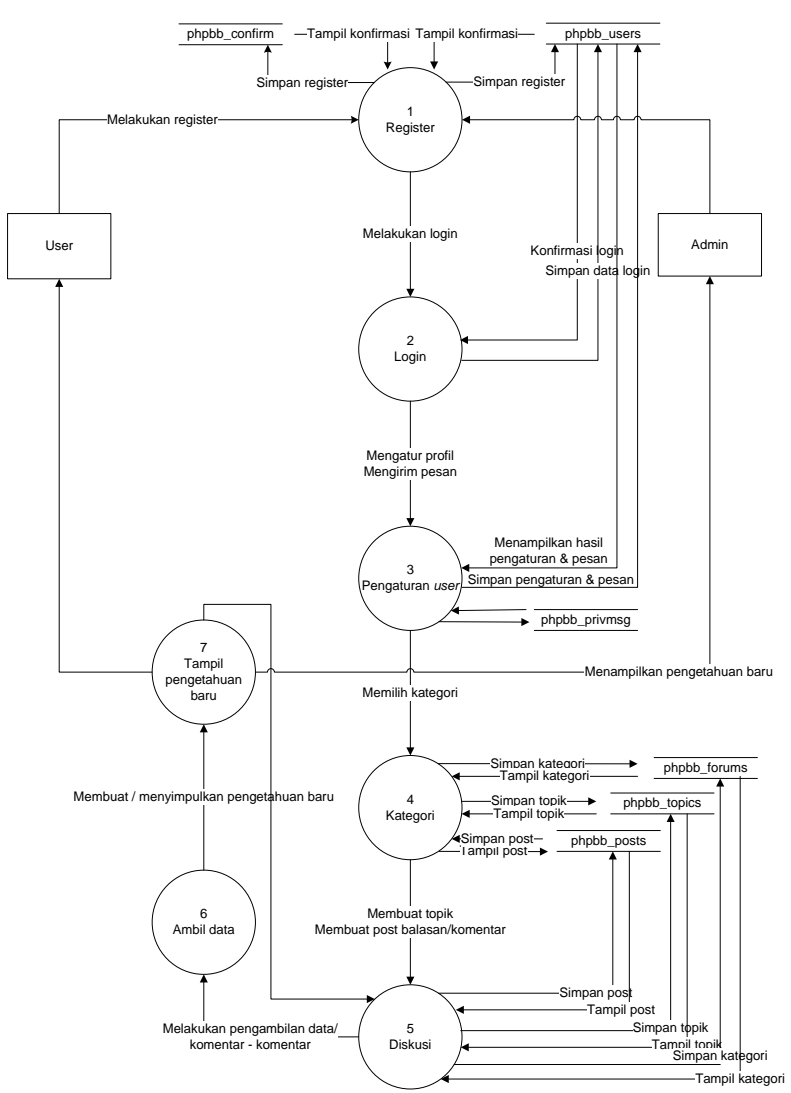

Gambar 5. Analisa Data Flow Diagram

Tabel II.

Deskripsi DFD Proses Register

\begin{tabular}{|ll|}
\hline No. Proses & $: 1$ \\
Nama proses & : Register \\
Deskripsi & : registrasi user \\
Masukan & : data user \\
Keluaran & : Halaman login \\
\hline
\end{tabular}

Tabel III.

Deskripsi DFD Proses Login

\begin{tabular}{|c|c|}
\hline No. Proses & $: 2$ \\
\hline Nama proses & : Login \\
\hline Deskripsi & $\begin{array}{l}\text { : login untuk memasuki forum } \\
\text { diskusi }\end{array}$ \\
\hline Masukan & : username, dan password user \\
\hline Keluaran & : halaman indeks \\
\hline
\end{tabular}

Tabel IV.

Deskripsi DFD Pengaturan User

\begin{tabular}{|ll|}
\hline No. Proses & $: 3$ \\
Nama proses & : Pengaturan User \\
Deskripsi & : Mengatur halaman, mengirim \\
& pesan \\
Masukan & $:$ Statement dalam database \\
Keluaran & : Statement dalam bentuk text \\
file & \\
\hline
\end{tabular}

Tabel 3.5.

Deskripsi Kategori

\begin{tabular}{|c|c|}
\hline No. Proses : & \\
\hline Nama proses: & : Kategori \\
\hline Deskripsi & $\begin{array}{l}\text { : Memilih kategori untuk } \\
\text { memasuki forum }\end{array}$ \\
\hline Masukan & : pilih kategori forum \\
\hline Keluaran & kategori forum yang dipilih \\
\hline
\end{tabular}

Tabel V.

Deskripsi Diskusi

\begin{tabular}{|ll|}
\hline No. Proses & $: 5$ \\
Nama proses & $:$ Diskusi \\
Deskripsi & $:$ Input komentar \\
Masukan & $:$ Komentar \\
Keluaran & $:$ Komentar yang telah \\
diinputkan & \\
\hline
\end{tabular}

Tabel VI.

Deskripsi Ambil Data

\begin{tabular}{|ll|} 
No. Proses & $: 6$ \\
Nama proses & $:$ Ambil Data \\
Deskripsi & : Login admin dan \\
& $\begin{array}{l}\text { pengambilan komentar untuk } \\
\text { digabungkan untuk membuat } \\
\text { pengetahuan baru }\end{array}$ \\
& : sername, dan password \\
Masukan & : Halaman Admin \\
admin & \\
\hline
\end{tabular}

Tabel VII.

Deskripsi Tampil Pengetahuan Baru

\begin{tabular}{|ll|}
\hline No. Proses & $: 7$ \\
Nama proses & : Pengetahuan Baru \\
Deskripsi & : Menampilkan pengetahuan \\
& baru yang sekaligus dijadikan \\
& topik baru \\
Masukan & : Pengetahuan baru \\
Keluaran & : Pengetahuan baru dan topik \\
baru & \\
\hline
\end{tabular}

\section{HASIL}

A. Perangkat Lunak

Perangkat lunak yang dibutuhkan adalah sebagai berikut:

a. $X A M P P$

b. phpBB sebagai Content Management System (CMS) sebagai media diskusi.

Langkah-langkah dalam implementasinya system, pertama Install Xampp, lalu buat database untuk phpBB. Setelah database dibuat installasi phpBB. 


\section{B. Forum diskusi}

Pada forum diskusi topik Kualitas Buah Naga pertama kali ditentukan oleh moderator sebagai pembuka diskusi. Topik atau bahasan dapat diTopik tersebut sebagai proses tacit knowledge ke Explicit knowledge dan Explicit knowledge ke Explicit knowledge, dimana member yang telah terdaftar bisa memberikan komentar-komentarnya.

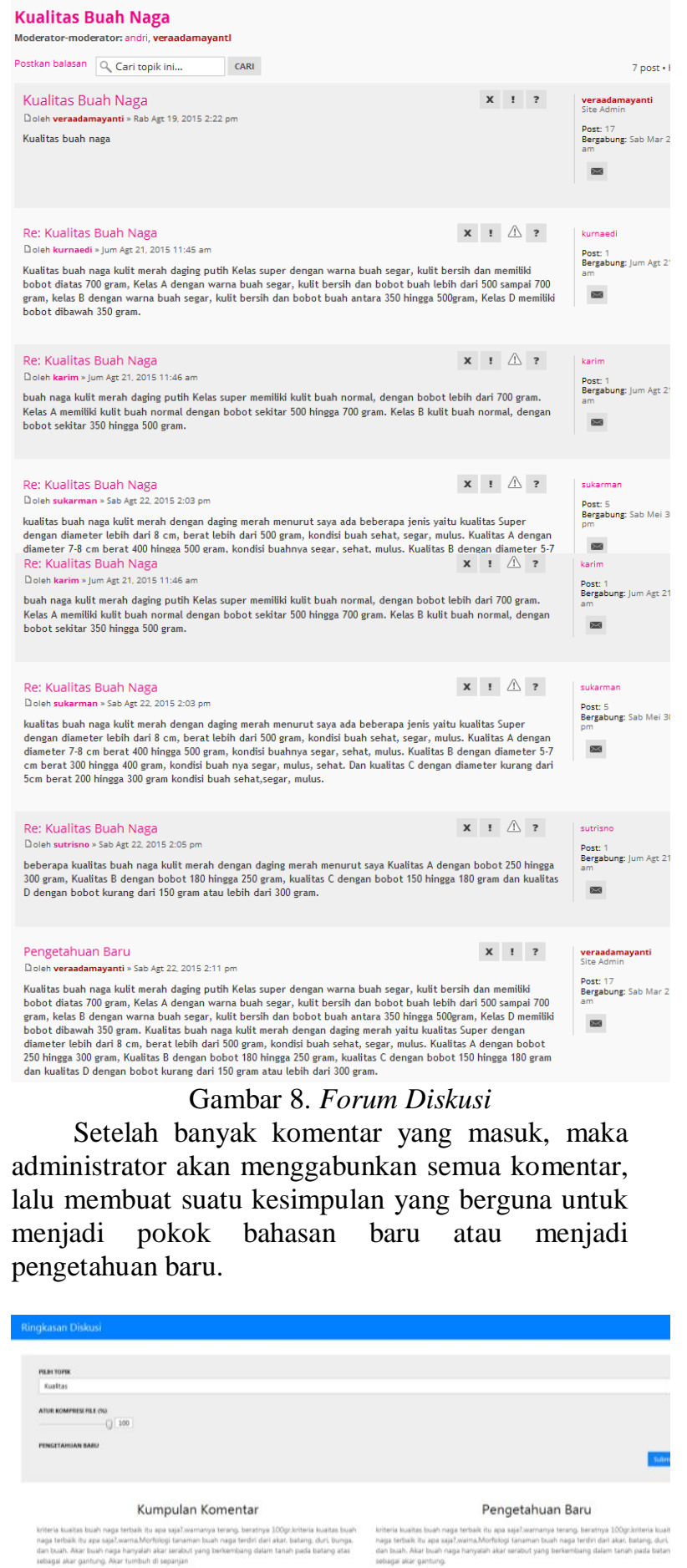

Gambar 9. Hasil dari komentar-komentar

\section{KESIMPULAN}

Simpulan dari penelitian ini adalah:

1. Penelitian ini menghasilkan sebuah model dalam penerapan knowledge management system dalam bentuk forum diskusi berbasis web untuk para petani buah naga.

2. Proses create knowledge dan sharing knowledge didapat dari komentar - komentar yang telah didiskusikan di forum.

3. Model yang digunakan pada proses pengumpulan pengetahuan baru yaitu model SECI, dimana langkah awal yang dilakukan adalah wawancara (sosialization), lalu hasil wawancara tersebut dirangkum dan dijadikan topik dan pembahasan. Petani akan memberikan kontribusi berupa komentar (eksternalization). Selanjutnya komentar - komentar dari para petani tersebut digabungkan lalu diringkas kembali (combination), kemudian dari hasil ringkasan tersebut ditampilkan lagi sehingga hasilnya dapat dibaca kembali oleh para petani (internalization). Hasil ringkasan tersebut dapat diangkat kembali menjadi sebuah topik sehingga dari proses internalization dapat kembali lagi menjadi sosialization (didiskusikan kembali). Begitu seterusnya sesuai dengan siklus knowledge management.

\section{DAFTAR PUSTAKA}

ALAVI, MARYAM, \& DOROTHY E. LEIDNER., 2001. Review: Knowledge Management and Knowledge Management Systems: Conceptual Foundations and Research Issues." MIS Quarterly 25, no. 1.

BOUTHILLIER, F., SHEARER, K., 2002. Understanding Knowledge Management and Information Management: The Need for an Empirical Perspective, Information Research, Vol. 8 No. 1, October.

BRINK, VAN DE. P., 2001. Measurement of Conditions for Knowledge Sharing, Proceedings 2nd European Conference on Knowledge Management, Bled.

DAVENPORT, THOMAS H \& PRUSAK, L., 2000. Working Knowledge : How Organizations Manage What They Know. Boston: Harvard Business School Press.

FRANCE BOUTHILLIER \& KATHLEEN SHEARER, 2002. Information Research, Vol. 8 No. 1.

MACMORROW, N., 2001. Knowledge Management: an Introduction, in: Annual Review of Information Science and Technology, edited by M.E. Williams. pp. 381-422. Medford, NJ: Information Today.

MAIER, R., DAN HÄDRICH, T., 2006. Knowledge Management Systems. Knowledge 
Management: Concepts, Methodologies, Tools, and Applications.

MARTENSSON, M., 2002. A Critical Review of Knowledge Management as a Management Tool. Journal of Knowledge Management, 4, 204-216.

NONAKA, IKUJIRO AND TAKEUCHI, HIROTAKA, 1995, The KnowledgeCreating Company: How Japanese Companies Create the Dynamics of Innovation. Oxford: Oxford University Press.

PRATOMO., 2008. Superioritas Jambu Biji dan Buah Naga.

STEIN, E. W., \& ZWASS, V., 1995. Actualizing Organizational Memory with Information Systems,. Information Systems Research $(6: 2)$.

SWASTIKA, S., Y. NURMILI DAN S. SUHENDRI., 2012. Hama dan Penyakit Buah Naga. Balai Pengkajian Teknologi Pertanian Riau - Badan Penelitian dan Pengembangan Pertanian. Kementerian Pertanian. Pekanbaru.

TIWANA, A., 2000. The Knowledge Management Toolkit: Orchestrating IT, Strategy and Knowledge Management Platforms. Upper Saddle River, NJ: Prentice Hall.

TURBAN, E., 2008. Information Technology for Management - Transforming Organizations in the Digital Economy, 6th Edition ed. Hoboken: John Wiley \& Sons, 2008. 